\title{
Human Memory Retrieval and Inhibitory Control in the Brain: Beyond Correlational Evidence
}

\author{
Barbara Penolazzi, ${ }^{1}$ Davide Francesco Stramaccia, ${ }^{2}$ Miriam Braga, ${ }^{2}$ Sara Mondini, ${ }^{1,3,5}$ and Giovanni Galfano ${ }^{2,4}$ \\ Departments of ${ }^{1}$ General Psychology and ${ }^{2}$ Developmental and Social Psychology, ${ }^{3}$ Human Inspired Technologies Research Centre-HIT, and ${ }^{4} \mathrm{Center}$ for \\ Cognitive Neuroscience, University of Padua, I-35131 Padua, Italy, and ${ }^{5}$ Figlie di S. Camillo, Neuropsychology Clinic, I-26100 Cremona, Italy
}

Retrieving information from long-term memory can result in the episodic forgetting of related material. One influential account states that this retrieval-induced forgetting (RIF) phenomenon reflects inhibitory mechanisms called into play to decrease retrieval competition. Recent neuroimaging studies suggested that the prefrontal cortex, which is critically engaged in inhibitory processing, is also involved in retrieval competition situations. Here, we used transcranial direct current stimulation (tDCS) to address whether inhibitory processes could be causally linked to RIF. tDCS was administered over the right dorsolateral prefrontal cortex during the retrievalpractice phase in a standard retrieval-practice paradigm. Sixty human participants were randomly assigned to anodal, cathodal, or sham-control groups. The groups showed comparable benefits for practiced items. In contrast, unlike both the sham and anodal groups, the cathodal group exhibited no RIF. This pattern is interpreted as evidence for a causal role of inhibitory mechanisms in episodic retrieval and forgetting.

Key words: cognitive control; DLPFC; inhibition; memory; retrieval; tDCS

\section{Introduction}

Retrieving information from long-term memory is known to elicit two well established phenomena. On the one hand, processing of the retrieved items is enhanced, an effect known as retrieval-induced facilitation (FAC). On the other hand, however, processing of items related to those that have been retrieved is impaired, resulting in a phenomenon called retrieval-induced forgetting (RIF; Anderson et al., 1994). These effects have typically been studied with the retrieval-practice paradigm (Levy and Anderson, 2002), in which participants first learn several categoryexemplar pairs from several categories (study phase) and then actively retrieve some of the studied exemplars of half categories only (retrieval-practice phase). The final phase (test phase) consists of a recall test involving all learned exemplars. Typically, the FAC effect consists of a better recall of practiced items over unpracticed items from unpracticed categories (i.e., control items), whereas the RIF effect consists of a better recall of control items over unpracticed items from practiced categories.

RIF has proved a robust effect and has been replicated in a variety of domains (Johnson and Anderson, 2004; Galfano et al., 2011). According to an influential class of models, RIF would reflect inhibitory mechanisms actively engaged by retrieval pro-

\footnotetext{
Received Jan. 26, 2014; revised April 4, 2014; accepted April 5, 2014.

Author contributions: B.P., D.F.S., M.B., S.M., and G.G. designed research; B.P., D.F.S., and M.B. performed research; B.P., D.F.S., M.B., and G.G. analyzed data; B.P., D.F.S., S.M., and G.G. wrote the paper.

We thank two anonymous reviewers and Carlo Umiltà for their helpful comments on a previous version of this manuscript.

The authors declare no competing financial interests.

Correspondence should be addressed to Giovanni Galfano, Department of Developmental and Social Psychology, University of Padua, Via Venezia, 8, I-35131, Padova, Italy. E-mail: giovanni.galfano@unipd.it.

DOI:10.1523/JNEUROSCI.0349-14.2014

Copyright $\odot 2014$ the authors $\quad 0270-6474 / 14 / 346606-05 \$ 15.00 / 0$
}

cessing during the practice phase, aimed to maximize the retrieval of the to-be-practiced items (Anderson, 2003; for review, see Storm and Levy, 2012). Crucially, according to inhibitory accounts, facilitation of practiced items is functionally independent from forgetting of unpracticed, related competitors, whereas, according to non-inhibitory accounts, RIF and FAC are functionally related, because forgetting of unpracticed, related items is attributable to the strengthening of practiced items. Neuroimaging studies suggested that a broad prefrontal neural network, involved in executive control, is engaged during retrieval practice, and some of the activated areas within this network [i.e., anterior cingulate cortex, anterior ventrolateral prefrontal cortex, dorsolateral prefrontal cortex (DLPFC)] seem to be directly linked to forgetting of competitors, because their activation predicts the amount of RIF but not that of FAC (Kuhl et al., 2007; Wimber et al., 2008). Nevertheless, these data are correlative in nature. The present study aimed to establish a causal relationship between prefrontal areas and the specific cognitive mechanisms underlying RIF using transcranial direct current stimulation (tDCS), a non-invasive neuromodulation technique (Dayan et al., 2013). We targeted the DLPFC because fMRI data suggest that its activation correlates with the amount of RIF (Wimber et al., 2009) and is engaged in direct suppression of unwanted thoughts (Benoit and Anderson, 2012; Gagnepain et al., 2014). Based on previous neuromodulation studies investigating inhibitory control (Juan and Muggleton, 2012), active stimulation was delivered over the right hemisphere. tDCS was administered during the practice phase of a standard retrieval-practice paradigm, because inhibitory processes would act specifically during this phase according to inhibitory accounts (Anderson, 2003). If the right DLPFC plays a causal role in RIF and inhibition is a critical 


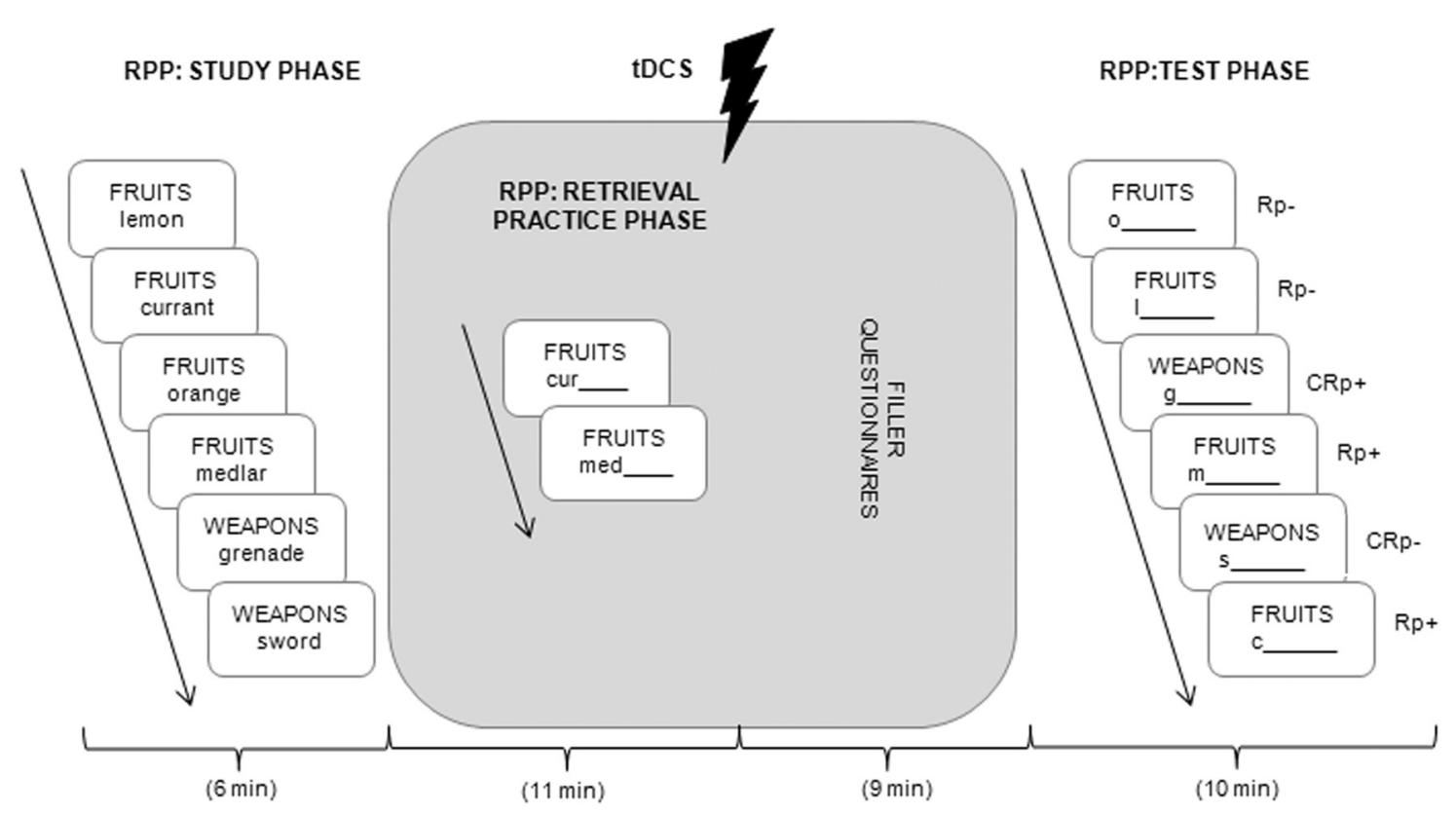

Figure 1. Schematic illustration of the experimental procedure. Participants took part in a standard retrieval-practice paradigm (RPP). Stimulation was administered during the phase in which inhibitory processes are assumed to occur according to inhibitory accounts. To maximize the probability of inducing neuromodulatory effects, stimulation lasted 20 min. Because the retrievalpractice phase lasted only $11 \mathrm{~min}$, participants completed filler questionnaires unrelated to the present research. The test phase was performed immediately after the end of the stimulation but after a brief delay with respect to the practice phase, in line with the standard RPP.

mechanism underlying such phenomenon, then we would expect no alterations of FAC but a significant, stimulation-dependent, alteration of RIF.

\section{Materials and Methods}

Participants. Sixty students (10 males; mean \pm SD, $23.4 \pm 2.1$ years), who met the inclusion criteria for participating in brain stimulation studies, gave their written informed consent to take part in the experiment, performed in accordance with the principles of the Declaration of Helsinki. The study, which adopted the safety procedures of non-invasive brain stimulation, was approved by the local ethical committee.

Materials and procedure. RIF was assessed using a standard retrievalpractice paradigm (Anderson et al., 1994). Stimuli were 96 Italian nouns of exemplars belonging to eight semantic categories selected from the categorical production norms for Italian language (Boccardi and Cappa, 1997). Criteria for stimuli selection were those generally used for this paradigm: (1) categories were relatively unrelated; (2) semantic associations between items of different categories were kept to a minimum; (3) only at least five letter items were included; and (4) within each category, each item had a unique first letter. In all categories, 7 of 12 items were strong exemplars (i.e., they were generated with a high frequency according to the production norms; mean number of produced exemplars, 73.7; range, 39.43-102.4), whereas the other five items were weak exemplars (i.e., they were generated with a low frequency according to the production norms; mean number of produced exemplars, 6.1; range, 1-16). Because weak exemplars suffer significantly less RIF than strong exemplars do (Anderson et al., 1994), to maximize the probability of eliciting the effect, weak exemplars served as to-be-practiced items, whereas strong exemplars served as unpracticed, related items.

As shown in Figure 1, in the first phase of the paradigm (study phase), participants studied the 96 category-exemplars pairs, randomly presented in a categorized blocked order. Each trial started with a fixation cross for $0.5 \mathrm{~s}$, followed by a blank lasting $0.5 \mathrm{~s}$, and a category-exemplar pair for $2.5 \mathrm{~s}$. The intertrial interval consisted of a blank lasting $0.5 \mathrm{~s}$. In the second phase (retrieval-practice phase), participants retrieved only weak exemplars from half of the studied categories through a cued-recall test. Specifically, items were randomly presented four times each, in the form category-plus-three-letter-stem (e.g., FRUITS-cur__). This allowed to distinguish items as follows: (1) practiced items from practiced categories $\left(\mathrm{Rp}^{+}\right.$; corresponding to weak exemplars); (2) unpracticed items from practiced categories $\left(\mathrm{Rp}^{-}\right.$; corresponding to strong exemplars); and (3) control items, i.e., unpracticed items from unpracticed categories [in turn, distinguished in weak exemplars $\left(\mathrm{CRp}^{+}\right)$acting as control for $\mathrm{Rp}^{+}$items and strong exemplars $\left(\mathrm{CRp}^{-}\right)$acting as control for $\mathrm{Rp}^{-}$items]. Each trial started with a fixation cross for $1 \mathrm{~s}$, followed by a blank lasting $1 \mathrm{~s}$, and an item for $4 \mathrm{~s}$. The intertrial interval lasted $1 \mathrm{~s}$. In the third phase (test phase), participants performed a cued-recall task (items in the form category-plus-one-letter-stem, e.g., FRUITS-o__), including all items studied in the first phase. Each trial started with a fixation cross lasting $0.5 \mathrm{~s}$, followed by a blank screen lasting $0.5 \mathrm{~s}$, and an item for $4 \mathrm{~s}$. The intertrial interval lasted $1 \mathrm{~s}$. To ensure that RIF was not caused by output interference (i.e., interference exerted by $\mathrm{Rp}^{+}$items, which tend to be recalled first), $\mathrm{Rp}^{-}$items were always tested before $\mathrm{Rp}^{+}, \mathrm{CRp}^{-}$, and $\mathrm{CRp}^{+}$items, which appeared in random order. Although this presentation order might have caused $\mathrm{CRp}^{-}$items to undergo more interference than $\mathrm{Rp}^{-}$items, such bias was held constant across participants and hence is unlikely to have influenced the results as a function of stimulation. Four balanced lists differing in the subgroups of categories acting as either to-be-practiced categories or control categories were built and randomly assigned to participants.

Stimulation was delivered during the retrieval-practice phase, in which inhibitory processes are assumed to operate according to inhibitory accounts. Because the retrieval-practice phase lasted less than the stimulation period, when the former finished, participants were asked to complete unrelated filler questionnaires until the end of the stimulation. When the stimulation finished, the test phase started.

A single-blind, sham-controlled, between-group design was used: participants were randomly assigned to one of three stimulation conditions (two active stimulations and one sham-placebo stimulation), without being informed about the kind of stimulation they received. Sample size for each group was determined a priori on the basis of both previous neuroimaging studies addressing RIF (Wimber et al., 2009) and neuromodulation studies implementing between-participants designs (Penolazzi et al., 2013).

To rule out alternative accounts of tDCS effects, a self-report questionnaire measuring mood and arousal was administered at both the beginning and the end of the experiment. In addition, to detect possible differences in the sensations experienced during the different stimulation 
Table 1. Mean percentage of recall in the retrieval-practice phase and in the final test phase as a function of both item type and stimulation group

\begin{tabular}{|c|c|c|c|c|c|}
\hline \multirow[b]{2}{*}{ Stimulation group } & \multirow{2}{*}{$\begin{array}{l}\text { Retrieval-practice phase } \\
\text { Item type } \\
\mathrm{Rp}^{+}\end{array}$} & \multicolumn{4}{|l|}{$\begin{array}{l}\text { Final test phase } \\
\text { Item type }\end{array}$} \\
\hline & & $\overline{\mathrm{Rp}^{+}}$ & $\mathrm{CRp}^{+}$ & $\mathrm{Rp}^{-}$ & $\mathrm{CRp}^{-}$ \\
\hline Sham & $74.61(69.44,79.79)$ & $59.75(52.94,66.56)$ & $24.25(19.26,29.24)$ & $30.18,(24.80,35.56)$ & $38.21(32.73,43.69)$ \\
\hline Anodal & $75.12(69.95,80.29)$ & $55.75(47.49,64.01)$ & $23.75(17.78,29.72)$ & $27.32(23.04,31.60)$ & $31.96(26.45,37.48)$ \\
\hline Cathodal & $77.50(72.33,82.67)$ & $62.75(55.22,70.28)$ & $20.75(16.44,25.06)$ & $27.68(22.07,33.28)$ & $23.75(18.63,28.87)$ \\
\hline
\end{tabular}

Lower and upper limits of $95 \% \mathrm{Cl}$ are reported in parentheses.

conditions, at the end of the experiment, participants were asked to complete a five-point-scale questionnaire (Fertonani et al., 2010).

$t D C S$. tDCS was delivered through a battery-driven current stimulator (BrainStim; EMS), using a pair of surface saline-soaked sponge electrodes $\left(16 \mathrm{~cm}^{2}\right)$. A constant current of $1.5 \mathrm{~mA}$ was applied for $20 \mathrm{~min}$ (fade-in/fade-out time, $60 \mathrm{~s}$ ) in both the active stimulation conditions. In the anodal group, the anode was positioned over the right DLPFC (F4 site of the 10-20 EEG system), whereas the cathode was positioned over the left supraorbital area, a commonly used site for the reference electrode. Although other regions are also known to be involved in RIF (Wimber et al., 2009), we focused on DLPFC for two critical reasons. First, DLPFC is critically engaged in inhibitory processing (Knoch et al., 2006; De Neys et al., 2008) and thought suppression (Benoit and Anderson, 2012). Second, DLPFC is more consistently identified as underlying a specific site of the 10-20 EEG system compared with other areas (e.g., ventrolateral prefrontal cortex). We focused on the right hemisphere because brain stimulation studies addressing motor inhibition highlighted its key role in inhibitory control (for review, see Juan and Muggleton, 2012). Furthermore, given the linguistic nature of our stimuli, we preferred to minimize the possible modulation of areas involved in linguistic processing. In the cathodal group, electrode positioning was reversed with respect to the anodal group. In the sham group, a $1.5 \mathrm{~mA}$ current was applied for $15 \mathrm{~s}$ at the beginning and $15 \mathrm{~s}$ at the end of the stimulation period.

Data analyses. A one-way ANOVA with group (anodal, cathodal, sham) as the between-participant factor was conducted on the percentage of correctly recalled items in the retrieval-practice phase. However, the crucial analyses to test our experimental hypothesis were related to the percentage of correctly retrieved items in the test phase. In this regard, a mixed-design ANOVA was performed for FAC, with group as a between-participant factor and item type $\left(\mathrm{Rp}^{+}, \mathrm{CRp}^{+}\right)$as a withinparticipant factor. An analogue ANOVA was performed for RIF, with group as a between-participant factor and item type $\left(\mathrm{CRp}^{-}, \mathrm{Rp}^{-}\right)$as a within-participant factor. For significant interactions, Bayesian analyses were used to disentangle which model (null vs alternative hypothesis) was more strongly supported by the available data. Specifically, the Bayesian information criterion (BIC) was computed to test the presence of the investigated effects (FAC and RIF) in each group (Masson, 2011). Within this framing, the posterior probability that the data favor the alternative hypothesis, i.e., $p_{\mathrm{BIC}}\left(H_{1} \mid \mathrm{D}\right)$, ranges from 0 to 1 and is just the complement of the posterior probability that the data favor the null hypothesis. Thus, $p_{\mathrm{BIC}}\left(H_{1} \mid \mathrm{D}\right)>0.50$ indicate that there is more evidence for the alternative than for the null hypothesis, whereas values $<0.50$ indicate the opposite. Finally, Pearson's correlations between FAC (i.e., $\mathrm{Rp}^{+}-\mathrm{CRp}^{+}$) and $\mathrm{RIF}$ (i.e., $\mathrm{CRp}^{-}-\mathrm{Rp}^{-}$), for both the entire sample and the three groups, were performed to further test the hypothesis of their independency, with positive correlations indicating that RIF increases as FAC increases.

\section{Results}

Table 1 shows the mean percentage of correct recall for $\mathrm{Rp}^{+}$ items during the retrieval-practice phase and for all item types during the test phase as a function of group. The analysis of the percentage of correct recall of $\mathrm{Rp}^{+}$items during the retrievalpractice phase showed that group did not affect the success rate in retrieval $\left(F_{(2,57)}=0.36, p=0.702, \eta_{\mathrm{p}}^{2}=0.01\right)$. Turning to the critical results related to the test phase, the ANOVA assessing the FAC effect only revealed a significant main effect of item type

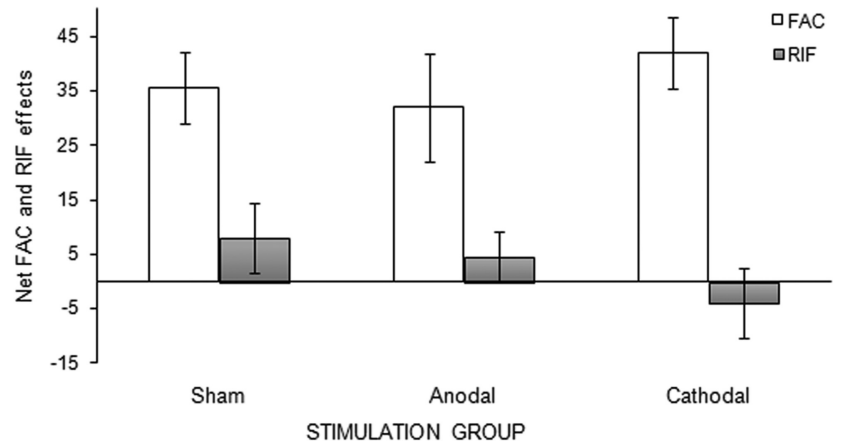

Figure 2. Recall data from the final test phase in the three groups. FAC is computed as follows: $\mathrm{FAC}=\left(\% \mathrm{Rp}^{+}\right)-\left(\% \mathrm{CRp}^{+}\right)$. RIF is computed as follows: RIF $=\left(\% \mathrm{CRp}^{-}\right)^{-}$ $\left(\% \mathrm{Rp}^{-}\right)$. Bars represent $95 \%$ Cls.

$\left(F_{(1,57)}=285.93, p<0.001, \eta_{\mathrm{p}}^{2}=0.83\right)$, indicating that $\mathrm{Rp}^{+}$ items were recalled better than $\mathrm{CRp}^{+}$items, regardless of the group [mean of $\mathrm{Rp}^{+}$items $\left(\mathrm{M}_{\mathrm{Rp}+}\right)=59.42 \%, 95 \% \mathrm{CI}_{\mathrm{Rp}+}=$ 55.24, 63.59; and $\left.\mathrm{M}_{\mathrm{CRp}+}=22.92 \%, 95 \% \mathrm{CI}_{\mathrm{CRp}+}=20.08,25.75\right]$. Neither the main effect of group $\left(F_{(2,57)}=0.25, p=0.778, \eta_{\mathrm{p}}^{2}=\right.$ $0.01)$ nor the group $\times$ item type interaction $\left(F_{(2,57)}=1.84, p=\right.$ $0.168, \eta_{\mathrm{p}}^{2}=0.06$ ) were significant (Fig. 2). Regarding RIF, the ANOVA showed a nonsignificant main effect of item type $\left(F_{(1,57)}\right.$ $\left.=3.35, p=0.073, \eta_{\mathrm{p}}^{2}=0.05\right)$ and a significant main effect of group $\left(F_{(2,57)}=4.11, p=0.022, \eta_{\mathrm{p}}^{2}=0.13 ; \mathrm{M}_{\text {Sham }}=34.20 \%\right.$, $95 \% \mathrm{CI}_{\text {Sham }}=30.00,38.39 ; \mathrm{M}_{\text {Anodal }}=29.64 \%, 95 \% \mathrm{CI}_{\text {Anodal }}=$ $\left.25.45,33.84 ; \mathrm{M}_{\text {Cathodal }}=25.71 \%, 95 \% \mathrm{CI}_{\text {Cathodal }}=21.52,29.91\right)$. Critical for the purpose of the study, the group $\times$ item type interaction was also significant $\left(F_{(2,57)}=4.98, p=0.01, \eta_{\mathrm{p}}^{2}=\right.$ 0.15 ; Fig. 2). Bayesian analyses showed that the posterior probability favoring the alternative hypothesis (presence of RIF, that is $\mathrm{CRp}^{-}$items recalled better than $\mathrm{Rp}^{-}$items) in the sham group was $p_{\mathrm{BIC}}\left(H_{1} \mid \mathrm{D}\right)=0.823$, which, according to the conventional categorization of degrees of evidence (Masson, 2011), constitutes a positive evidence for the presence of RIF in this group. Regarding the anodal group, the posterior probability favoring the alternative hypothesis was $p_{\mathrm{BIC}}\left(H_{1} \mid \mathrm{D}\right)=0.660$, which constitutes a weak evidence for the presence of RIF in this group. Crucially, the posterior probability favoring the alternative hypothesis in the cathodal group was $p_{\mathrm{BIC}}\left(H_{1} \mid \mathrm{D}\right)=0.338$, indicating that no RIF was present for this group. Correlations between FAC and RIF scores performed for both the entire sample and each of the three groups separately were not significant (highest $r=-0.39$ ).

Analyses of the self-report questionnaire measuring mood and arousal revealed no significant differences in any of the items as a function of stimulation conditions. With regard to the selfreport questionnaire assessing the sensations experienced during the stimulation, sham and active protocols were found to be indiscernible, because none of the assessed sensations significantly varied as a function of group. 


\section{Discussion}

In the present study, we tested whether RIF could be modulated by tDCS over the right DLPFC by administering stimulation during the retrieval-practice phase of a standard retrieval-practice paradigm. Retrieval-practice data showed that perturbing the practice phase by administering tDCS did not affect accuracy. Although this result might seem surprising, past work has shown that dividing attention with a concurrent task during retrieval practice does not impair retrieval success while disrupting inhibitory processes (Román et al., 2009). Regarding the data of the final test phase, FAC (i.e., the classic practice effect) was present in all stimulation groups, as practiced items were recalled better than control items regardless of group. Concerning RIF, sham and anodal stimulations induced a similar effect (although stronger for the sham group): unpracticed items from practiced categories were recalled significantly worse than control items. In sharp contrast, cathodal stimulation abolished RIF.

fMRI studies (Wimber et al., 2009) suggested that DLPFC, among the many prefrontal regions engaged in competitive retrieval practice, could have an active role in determining RIF, given that its recruitment during the practice phase predicted the amount of subsequent forgetting in the test phase. The present study, overcoming a correlational approach, provided the first data supporting a causal involvement of the right DLPFC in the functional genesis of RIF. However, this does not necessarily mean that this is the only area causally involved in the phenomenon. Similarly, given that tDCS electrode size is relatively large and transynaptic effects are also possible, one cannot rule out the possibility that the present electrode montage also resulted in influencing other areas, adjacent to the DLPFC, also involved in the neural circuitry underlying RIF. However, the critical point here is that the present results attest that the right DLPFC has a key role within the network involved in the suppression of unwanted episodic memories, as suggested by recent fMRI data (Benoit and Anderson, 2012). Importantly, a growing literature focusing on encoding, retrieval, and reconsolidation mechanisms showed that right lateral prefrontal cortex plays a pivotal role in episodic memory (Manenti et al., 2012; Sandrini et al., 2013). The present findings extend this body of evidence by showing that such a region is also relevant for episodic forgetting.

Beside providing topographical information concerning the neural network underpinning RIF, the present findings are also crucial for evaluating current theoretical perspectives concerning the functional mechanisms that allow us to overcome interference from competing memories.

At the functional level, RIF has been interpreted as reflecting two possible mechanisms (Storm and Levy, 2012) based on either inhibitory or non-inhibitory processes (the latter being often referred to as associative-interference accounts). Inhibitory accounts (Anderson, 2003) assume that inhibitory mechanisms are actively engaged during the practice phase to resolve retrieval competition by decreasing activation of the items related to those that have been practiced, in such a way that they would be less available with respect to control items in the test phase. In contrast, associative-interference accounts assume that the only mechanism active in the retrieval-practice phase is the strengthening of the category-item associations for items to be practiced. This reinforcement would block or weaken access to unpracticed, related competitors in the subsequent test phase, thus determining their retrieval disadvantage as a mere side effect. Crucially, according to inhibitory accounts, facilitation of practiced items is functionally independent from forgetting of unpracticed, related items, whereas, according to non-inhibitory accounts, RIF and FAC are functionally related, because forgetting of unpracticed items is attributable to the strengthening of practiced items. In this regard, our results, obtained by stimulating the right DLPFC when inhibitory mechanisms are assumed to act on interfering memories (Anderson, 2003), strongly support inhibitory accounts based on two arguments. First, stimulation-induced effects were obtained by perturbing an area of the right prefrontal cortex that is known to play an important role in inhibitory control according to studies addressing different cognitive domains (Knoch et al., 2006; De Neys et al., 2008). Second, the modulation of RIF in the absence of a concomitant modulation of FAC indicates a clear dissociation between the cortical key areas causally involved in these phenomena and, in turn, a dissociation between the underlying cognitive mechanisms. These dissociations are only consistent with inhibitory accounts, because associativeinterference accounts postulate a direct relationship between the extent to which unpracticed, related items are forgotten and the extent to which practiced items are strengthened (Mensink and Raaijmakers, 1988). In this regard, our findings not only fail to confirm the positive correlation predicted by associative-interference accounts but, in line with previous evidence (Weller et al., 2013), seem to go significantly against it, because the correlation between RIF and FAC, albeit not statistically significant, was inverse. This is consistent with evidence showing that the two phenomena are not only differentially sensitive to manipulations aimed to overload executive control processes (with only RIF being selectively affected by stress and dual-task requirements; Koessler et al., 2009 and Román et al., 2009, respectively) but also linked to different neurotransmitters (Wimber et al., 2011).

Although one may have expected a reduction in RIF as a result of better recall of $\mathrm{Rp}^{-}$items for the active stimulation groups than for the sham group, it is important to note that we used a between-participant design, and because active stimulation groups were not tested for RIF before receiving tDCS, we cannot rule out the possibility that the three groups were different in their baseline. Therefore, when referring to this type of design, it is safer to rely on comparisons involving differential (i.e., relative) rather than absolute scores, that is to focus on relative variations in the performance on the two key item types necessary to assess RIF and FAC within each group, and compare such effects. Although the combined use of brain stimulation and retrievalpractice paradigm may be difficult to implement in a withinparticipant design, future studies adopting such experimental logic may address this issue in a more straightforward manner.

Concerning the effects exerted by the two types of active stimulation used here, we did not find opposite behavioral effects of anode and cathode. Such a pattern might have been expected based on the fact that cortical excitability is increased by anodal stimulation and decreased by cathodal stimulation. However, these dual-polarity effects have not been reported consistently, especially in the cognitive domain (Penolazzi et al., 2010; Jacobson et al., 2012). Interestingly, the only study addressing motor inhibition processes indexed by the number of false alarms in a go/no-go task (Beeli et al., 2008) and delivering stimulation over the right DLPFC showed that, consistent with our findings, cathodal stimulation decreased inhibition, whereas anodal stimulation did not. This suggests that excitatory and inhibitory effects of anodal and cathodal stimulations may emerge by complex interactions between the stimulated areas and the task used to assess the behavioral effects of inhibitory control. The observed asymmetrical effect of anodal and cathodal stimulation does not change the meaning of the present results, which indicate that 
altering neural activity of the right DLPFC by administering tDCS during the retrieval practice of some items does not affect their subsequent retrieval but only the forgetting of unpracticed, related items. This stimulation-induced abolishment of RIF is likely dependent on active inhibition of competitor items and emphasizes the need for incorporating inhibitory mechanisms in general theories of episodic retrieval and forgetting at both behavioral and neural levels. Future studies should address the role of other areas potentially relevant for memory control and inhibitory processing (e.g., ventrolateral prefrontal cortex and the left DLPFC), whose involvement was demonstrated in fMRI studies addressing RIF-related phenomena (Wimber et al., 2009; Benoit and Anderson, 2012; Hanslmayr et al., 2012). The combined use of tDCS and neuroimaging techniques might provide additional critical insights for understanding the functional dynamics underlying the interplay between these areas in orchestrating episodic memory processes (Venkatakrishnan and Sandrini, 2012).

\section{References}

Anderson MC (2003) Rethinking interference theory: executive control and the mechanisms of forgetting. J Mem Lang 49:415-445. CrossRef

Anderson MC, Bjork RA, Bjork EL (1994) Remembering can cause forgetting: retrieval dynamics in long-term memory. J Exp Psychol Learn Mem Cogn 20:1063-1087. CrossRef Medline

Beeli G, Casutt G, Baumgartner T, Jäncke L (2008) Modulating presence and impulsiveness by external stimulation of the brain. Behav Brain Funct 4:33. CrossRef Medline

Benoit RG, Anderson MC (2012) Opposing mechanisms support the voluntary forgetting of unwanted memories. Neuron 76:450-460. CrossRef Medline

Boccardi M, Cappa SF (1997) Valori normativi di produzione categoriale per la lingua italiana. Giornale Italiano di Psicologia 24:425-436.

Dayan E, Censor N, Buch ER, Sandrini M, Cohen LG (2013) Noninvasive brain stimulation: from physiology to network dynamics and back. Nat Neurosci 16:838-844. CrossRef Medline

De Neys W, Vartanian O, Goel V (2008) Smarter than we think: When our brains detect that we are biased. Psychol Sci 19:483-489. CrossRef Medline

Fertonani A, Rosini S, Cotelli M, Rossini PM, Miniussi C (2010) Naming facilitation induced by transcranial direct current stimulation. Behav Brain Res 208:311-318. CrossRef Medline

Gagnepain P, Henson RN, Anderson MC (2014) Suppressing unwanted memories reduces their unconscious influence via targeted cortical inhibition. Proc Natl Acad Sci U S A 111:E1310-E1319. CrossRef Medline

Galfano G, Penolazzi B, Fardo F, Dhooge E, Angrilli A, Umiltà C (2011) Neurophysiological correlates of retrieval-induced forgetting in multiplication fact retrieval. Psychophysiology 48:1681-1691. CrossRef Medline

Hanslmayr S, Volberg G, Wimber M, Oehler N, Staudigl T, Hartmann T, Raabe M, Greenlee MW, Bäuml KH (2012) Prefrontally driven downregulation of neural synchrony mediates goal-directed forgetting. J Neurosci 32:14742-14751. CrossRef Medline

Jacobson L, Koslowsky M, Lavidor M (2012) tDCS polarity effects in motor and cognitive domains: a meta-analytical review. Exp Brain Res 216:1-10. CrossRef Medline
Johnson SK, Anderson MC (2004) The role of inhibitory control in forgetting semantic knowledge. Psychol Sci 15:448-453. CrossRef Medline

Juan CH, Muggleton NG (2012) Brain stimulation and inhibitory control. Brain Stimul 5:63-69. CrossRef Medline

Knoch D, Gianotti LR, Pascual-Leone A, Treyer V, Regard M, Hohmann M, Brugger P (2006) Disruption of right prefrontal cortex by lowfrequency repetitive transcranial magnetic stimulation induces risktaking behavior. J Neurosci 26:6469-6472. CrossRef Medline

Koessler S, Engler H, Riether C, Kissler J (2009) No retrieval-induced forgetting under stress. Psychol Sci 20:1356-1363. CrossRef Medline

Kuhl BA, Dudukovic NM, Kahn I, Wagner AD (2007) Decreased demands on cognitive control reveal the neural processing benefits of forgetting. Nat Neurosci 10:908-914. CrossRef Medline

Levy BJ, Anderson MC (2002) Inhibitory processes and the control of memory retrieval. Trends Cogn Sci 6:299-305. CrossRef Medline

Manenti R, Cotelli M, Robertson IH, Miniussi C (2012) Transcranial brain stimulation studies of episodic memory in young adults, elderly adults and individuals with memory dysfunction: a review. Brain Stimul 5:103109. CrossRef Medline

Masson MEJ (2011) A tutorial on a practical Bayesian alternative to nullhypothesis significance testing. Behav Res Methods 43:679-690. CrossRef Medline

Mensink GJ, Raaijmakers JGW (1988) A model for interference and forgetting. Psychol Rev 95:434-455. CrossRef

Penolazzi B, Di Domenico A, Marzoli D, Mammarella N, Fairfield B, Franciotti R, Brancucci A, Tommasi L (2010) Effects of transcranial direct current stimulation on episodic memory related to emotional visual stimuli. PLoS One 5:e10623. CrossRef Medline

Penolazzi B, Pastore M, Mondini S (2013) Electrode montage dependent effects of transcranial direct current stimulation on semantic fluency. Behav Brain Res 248:129-135. CrossRef Medline

Román P, Soriano MF, Gómez-Ariza CJ, Bajo MT (2009) Retrieval-induced forgetting and executive control. Psychol Sci 20:1053-1058. CrossRef Medline

Sandrini M, Censor N, Mishoe J, Cohen LG (2013) Causal role of prefrontal cortex in strengthening of episodic memories through reconsolidation. Curr Biol 23:2181-2184. CrossRef Medline

Storm BC, Levy BJ (2012) A progress report on the inhibitory account of retrieval-induced forgetting. Mem Cognit 40:827-843. CrossRef Medline

Venkatakrishnan A, Sandrini M (2012) Combining transcranial direct current stimulation and neuroimaging: novel insights in understanding neuroplasticity. J Neurophysiol 107:1-4. CrossRef Medline

Weller PD, Anderson MC, Gómez-Ariza CJ, Bajo MT (2013) On the status of cue independence as a criterion for memory inhibition: evidence against the covert blocking hypothesis. J Exp Psychol Learn Mem Cogn 39:1232-1245. CrossRef Medline

Wimber M, Bäuml KH, Bergström Z, Markopoulos G, Heinze HJ, Richardson-Klavehn A (2008) Neural markers of inhibition in human memory retrieval. J Neurosci 28:13419-13427. CrossRef Medline

Wimber M, Rutschmann RM, Greenlee MW, Bäuml KH (2009) Retrieval from episodic memory: neural mechanisms of interference resolution. J Cogn Neurosci 21:538-549. CrossRef Medline

Wimber M, Schott BH, Wendler F, Seidenbecher CI, Behnisch G, Macharadze T, Bäuml KH, Richardson-Klavehn A (2011) Prefrontal dopamine and the dynamic control of human long-term memory. Transl Psychiatry 1:e15. CrossRef Medline 